Keywords: Conservation; Synthetic biology; biodiversity

\title{
Is it time for synthetic biodiversity conservation?
}

\section{Authors:}

*Antoinette J. Piaggio United States Department of Agriculture, National Wildlife Research Center, 4101 LaPorte Avenue, Fort Collins, CO 80521, USA

*Philip J. Seddon Department of Zoology, University of Otago, PO Box 56, Dunedin 9016, New Zealand

*Gernot Segelbacher Wildlife Ecology and Management, University of Freiburg, D79106 Freiburg, Germany

Luke Alphey, Arthropod Genetics Group, The Pirbright Institute, Ash Road, Woking, GU24 0NF, UK, AND Department of Zoology, University of Oxford, South Parks Road, Oxford, OX1 3PS, UK

Elizabeth L. Bennett, Wildlife Conservation Society, 2300 Southern Boulevard, Bronx, NY 10460, USA

Robert H. Carlson Biodesic, Seattle, WA 98103

Robert M. Friedman, J. Craig Venter Institute, 4120 Capricorn Lane, La Jolla, CA 92037, USA

Dona Kanavy, Department of Molecular and Cellular Medicine, Texas A\&M University, 440 Reynolds Medical Building, College Station, TX 77843, USA

Ryan Phelan, Revive \& Restore, 2 Marina Boulevard Building A, San Francisco, CA 94123, USA

Kent H. Redford, Archipelago Consulting, Box 4750, Portland, Maine, USA \& Department of Environmental Studies, University of New England, Biddeford, Maine, 04112, USA.

Marina Rosales Benites de Franco, Federico Villarreal National University, Av. Oscar R. Benavides 450. 4to Piso., Lima. Perú.

Lydia Slobodian, Environmental Law Centre, Godesberger Allee 108-112, 53175, IUCN, Bonn, Germany

Keith Wheeler, Chairman and CEO, ZedX Inc. and Chair Emeritus, IUCN-CEC * joint first authors in alphabetical order 


\section{Abstract:}

38 Evidence indicates that, despite some critical successes, current conservation

39 approaches are not slowing the overall rate of biodiversity loss. The field of synthetic 40 biology, which is capable of altering natural genomes with extremely precise editing, 41 might offer the potential to resolve some intractable conservation problems (e.g.

42 invasive species or pathogens). However, it is our opinion that there has been

43 insufficient engagement by the conservation community with practitioners of

44 synthetic biology. We contend that rapid, large-scale engagement of these two

45 communities is urgently needed to avoid unintended and deleterious ecological

46 consequences. To this point we describe case studies where synthetic biology is

47 currently being applied to conservation and we highlight the benefits to conservation 48 biologists from engaging with this emerging technology. 
51 Despite decades of conservation action and two global initiatives under the auspices

52 of the Convention on Biological Diversity, current indications are that we have been

53 unable to slow the rate of biodiversity loss [1-3]. Even with increasing terrestrial and

54 marine areas under some form of protection, current protected area networks are

55 considered to be insufficient to stem biodiversity loss [1, 4]. Further, degradation of

56 protected areas, the impacts of invasive species, emerging infectious diseases, and

57 even societal denial of biodiversity loss threaten to turn back the progress that has

58 been made [1, 5]. Consequently there have been calls for bolder conservation thinking

$59[6]$, such as engagement with new technologies, including those emerging from the

60 field of synthetic biology [7, 8].

Synthetic biology is a rapidly expanding field where engineering principles are applied to the construction of biological parts and systems, resulting in new and desired traits they wouldn't have in their original or natural state $[9,10]$. Recently, the

65 field of synthetic biology has facilitated technological advances by adding the powerful capability of genome editing through deleting a target gene and/or inserting a synthetic one, now typically using CRISPR/Cas9 endonucleases $[11,12]$ (a graphical illustration of this technique can be found in figure 3 [12]). This, paired with harnessing the power of gene drives, which can be synthesized or naturally occurring [13], and other new synthetic techniques, bring the efficacy of genetic modification to a new level. Further, this capability of genetic modification is

72 cheaper, easier, more precise, and more rapid than ever before, and thus widely 73 accessible. It has become apparent that synthetic biology holds tremendous potential 
across numerous fields, including conservation biology. With such tools in hand conservation of biodiversity could become proactive rather than reactive. What if we could engineer mosquitoes, which are invasive in Hawai'i, with a synthesized gene or genetic pathway so that they are no longer capable of transmitting the avian blood parasite that has devastated endemic bird populations [14]? Or perhaps, using the techniques of synthetic biology, scientists could produce male mosquitoes that produce only male offspring when they breed with wild-type females, thus driving populations locally extinct [15]? What if burgeoning human populations could be fed with reduced or minimized impacts to biodiversity [2]? Through these examples and others presented here [Table 1] the potential of synthetic biology to aid biodiversity conservation efforts is apparent. However, lack of understanding of the technology, the speed of developments, a potential for unforeseen outcomes, and the prospect of altering natural systems, have held conservation biologists back from engaging with synthetic biology. In fact, some conservation activists have recently called for a moratorium on research of gene drives [16]. (1)

Some conservation biologists have recognized the potential of synthetic biology for biodiversity conservation and called for dialogue between the conservation and synthetic biology communities [8, 17-18]. Initially, members of the two communities sat down formally in April 2013 [17] at a workshop in Cambridge, UK, with the explicit goal of exploring areas of mutual interest and identifying concerns.

Subsequently, some of the same participants along with new members from both communities took part in a workshop in Sausalito, California in April 2015. This workshop had three goals; i) educate conservationists about the application of these new tools and their potential benefits and risks; ii) inform synthetic biologists about 
urgent conservation problems that have thus far been intractable to conservation efforts; iii) identify a subset of the cases presented at the meeting that offer the best opportunity for tool development and application (http://longnow.org/revive/meetingreport/). This was the first attempt at identifying real-world problems that traditional conservation approaches have been unable to solve, but that might realistically be addressed by synthetic biology.

Most recently, in December 2015, a meeting was held between conservation and synthetic biologists at the Rockefeller Foundation Bellagio Center in Bellagio, Italy. This meeting was led by the International Union for Conservation of Nature (IUCN) and sought to: i) understand the relevance of synthetic biology to IUCN's mission and vision; ii) identify ways in which synthetic biology might have a positive impact on conservation issues, but also the potential negative impacts, and ways to mitigate these; iii) discuss the future of synthetic biology, its role in international biodiversity conservation, and ways to influence the trajectory of the application of synthetic biology to conservation. As participants in the Bellagio meeting we identified a critically urgent need for immediate and broad engagement of the conservation community with synthetic biology practitioners. Here, we look at two case studies of currently intractable conservation problems where synthetic biology solutions are being sought [Box 1 and Box 2]. Further, we consider other biodiversity problems in detail [Table 1], identify likely risks, uncertainties, points of concern within the conservation community, and potential mitigation of these concerns. Our goal is to stress the critical need for conservation biologists to apply their expertise in investigating the use of synthetic biology as a possible tool to be added to the biodiversity conservation toolbox [19]. Further, we emphasize that synthetic biology 
124 will be applied to global environmental issues with or without conservation

125 biologists' expertise. The robust science needed to ensure safe and successful

126 application will be more assured with the participation of conservation biologists. We

127 conclude by suggesting some guiding principles for the integration of synthetic

128 biology and conservation biology. Considering the moral, ethical, and aesthetic issues

129 associated with intentional direct human modification of a wild species, we call for

130 the development of a robust decision-making, risk-assessment framework, and

131 research to be conducted on the application of synthetic biology to conservation

132 issues.

133

\section{Conservation crisis}

136 Biological diversity is the currency of conservation, but by all indications we are

137 losing the battle to slow biodiversity loss. An evaluation of the outcomes of a 2002

138 major global commitment to slow the rate of biodiversity loss showed that by the

1392010 deadline key indicators of biodiversity had declined, while pressures on natural

140 systems had increased [1]. In 2010, due to the continued loss of biodiversity, another

141 attempt was made to secure global agreement on a set of ambitious biodiversity-

142 related "Aichi Targets" to be achieved by 2020 (Secretariat of the Convention on

143 Biological Diversity COP-10 Decision X/2). However, interim analyses indicate that,

144 despite some local successes, and improved responses and policies, rates of

145 biodiversity loss have not slowed and thus the 2020 targets are unlikely to be

146 achieved [3]. While protecting geographic areas is a major focus of biodiversity

147 conservation [5] other conservation tools take a single species management approach

148 or regulate drivers of biodiversity loss such as pollution, invasive species, land use 
change, and climate change. The estimated cost of protecting, monitoring, and managing terrestrial conservation sites for a single animal taxon, such as birds, is in excess of US\$65 billion annually [20]. Most countries cannot sustain such economic costs. Although the overall rate of biodiversity loss has not been slowed, without current efforts many more species would be threatened and/or extinct [21].

\section{Conservation and synthetic biology}

Most conservationists acknowledge that more tools are needed to slow the loss of

158 biodiversity. In fact, there have been attempts to adopt more risky, and therefore

159 controversial conservation interventions, such as assisted colonization to mitigate

160 climate-change-induced habitat alterations [22], or ecosystem restoration using

161 ecological replacements [23]. But these have been resisted by some within the

162 conservation community due to justifiable concerns around unanticipated deleterious

163 impacts on recipient ecosystems and/or further alterations to natural systems [24, 25].

164 Given that conservation biologists have been characterized as scientists "wishing to

165 pool their knowledge and techniques to solve problems" [26], and to seek novel

166 interdisciplinary connections and practices, why have they, as a community, generally

167 "paid little attention to synthetic biology", and been "timid" to engage in this body of 168 knowledge and techniques [7]? Instead, as the conservation community has become 169 aware of synthetic biology there has been resistance and fear from some, although not 170 all, sectors $[7,27]$.

172 We see several points of contention that have emerged from those that call for 173 synthetic biology to be in abeyance: i) technology has been responsible for many of 
174 the plights of the natural world and it is unlikely that technology can also address

175 these plights; ii) once we start making human-made changes to genomes, natural

176 selection may take over and begin to modify the modifications we have made; iii)

177 representing a value-based position, the idea of synthetic biology applied to

178 conservation is often accused of being equivalent to "playing God." This represents a

179 philosophical rather than scientific view about the importance of leaving nature alone;

180 iv) synthetic biology technologies might be patented and we would then be left with

181 difficult decisions about how to separate profit-driven motives from public-good

182 initiatives. Questions then arise such as: who will "own" endangered species modified

183 by patented technologies? v) Synthetic-biology-driven approaches might spread

184 modified genes to wild relatives, and might also create land use changes that will

185 further stress endangered ecosystems; vi) the development of new and modified crops

186 grown to provide feedstock for synthetic biology-altered microorganisms (especially

187 those developed for fuel production) might have an impact on both ecosystems and

188 the rural poor. We acknowledge all of these concerns and we do not dismiss them, but

189 we suggest they are not facts, but rather hypotheses to be tested with rigorous science.

190 We argue that the answer to these questions lies in the scientific engagement of

191 experts from conservation biology and other fields, robust research, and ecological

192 risk assessments [28].

194 The concerns listed above are not new; there have been over 40 years of genetic

195 modification of organisms and synthetic biology is part of this continuum. What is

196 unique to synthetic biology is the ease of the application. The National Academies of

197 Sciences, Engineering, and Medicine recently observed that research of gene drives

198 has already greatly exceeded the pace of research on population genetics and 
ecosystem dynamics [28]. These subjects are clearly within the purview of conservation biology and must continue to be advocated for especially for proposed releases of organisms with modified genomes. It is improbable that calls for moratoria will slow the advances or applications of synthetic biology. In fact, it can be a disservice to the goal of protecting biodiveristy if conservationists do not participate in applying the best science and thinkers to these issues. Several international organizations are striving to debate how to create frameworks and regulations for synthetic biology [28-30]. However, we have not even begun to debate the role of synthetic biology in biodiversity conservation, although at the IUCN World Conservation Congress in September 2016, Resolution 095 was passed by consensus, with calls for the IUCN to develop an approach for engaging with the synthetic biology community [31]. We hope by presenting our opinion that this necessary conversation will begin and that robust scientific engagement will follow.

Synthetic biology hybridizes engineering and biology and has two main areas: (i) genome redesign for new and desired traits, and (ii) faster and more reliable fabrication techniques for parts and systems that do not exist in the natural world. The discovery of techniques such as gene drives and CRISPR has led to an explosion of synthetic biology research in the past few years. Recently, not only have synthetic biology research projects increased exponentially, but so too has the interest in the economic potential of bio-products from the application of synthetic biology methods [32]. The economic motivation to develop and deploy these technologies is strongly driving a rapid pace of development. Events such as emerging infectious diseases, and the effects of climate change, will constitute even stronger incentives. While researchers have been able to work with genetically modified organisms for about 
224 four decades now, the cheap, easy, and precise tools now available through synthetic

225 biology make it possible to alter the genetic code of organisms or even create novel

226 ones rapidly and inexpensively. Synthetic biology is characterized by extremely fast

227 technological developments and a mindset that the future need not look like the past,

228 including future biological systems. This perspective stands in stark contrast to that

229 of conservation biology currently, which, despite the value of sustainable use being

230 acknowledged, is essentially preservation minded [7]. We argue that $21^{\text {st }}$ century

231 conservation philosophy should embrace concepts of synthetic biology and both seek

232 and guide appropriate synthetic solutions to aid biodiversity.

\section{Synthesis of Conservation and Synthetic Sciences}

236 We suggest it is necessary to adapt the culture of conservation biologists to a rapidly 237 changing reality. The current paradigm is not accomplishing radical positive change 238 nor adequately slowing anthropogenic destruction of habitat and biodiversity. To 239 make progress, we need to continue to push for more of the same solutions that we 240 know can succeed (e.g., a greater proportion of the planet being set aside for

241 protection per [6]). But we must also embrace new technologies and methodologies.

242 There is a consequent immediate need for the conservation community to more fully 243 engage with synthetic biology: (i) to understand potential and identify risks through 244 applying their expertise to robust risk assessments; (ii) to advise synthetic biologists 245 of environmental concerns and issues; (iii) to head off possibly ecologically damaging 246 initiatives; and (iv) to identify the most appropriate conservation problems for the 247 development and implementation of acceptable synthetic biology solutions. In fact, 248 some intractable conservation issues already have synthetic biology approaches being 
applied to them (Box 1 and Box 2). These examples represent flagships for many conservation issues (i.e. invasive species and emerging diseases), and also demonstrate that the application of synthetic biology to conservation issues is

252 occurring presently. Further, the application to wild systems has been outlined and a 253 roadmap developed [12].

[Table 1]

[Box 1] Case study 1: eradication of pest species

[Box 2] Case study 2: management of wildlife disease

\section{Guiding principles for the way forward}

We offer the following guiding principles for those involved in biodiversity conservation to recognize their responsibility in participating in synthetic biology and as recommendations for scientifically rigorous application of this technology to conservation problems:

\section{Responsible Stewardship}

The Presidential Commission for the Study of Bioethical Issues outlined five guiding

271 principles for their evaluation of synthetic biology, one of which was "responsible

272 stewardship" [33]. We reiterate this concept here as we believe it is one that the

273 conservation community should adopt wholeheartedly. Responsible stewardship as 
274 defined by [34] is our responsibility as humans and stewards of the natural world to

275 not take extreme stances on new technologies. We should neither embrace them

276 completely nor set out to block them for fear of unintended consequences.

277 "Responsible stewardship rejects positions that forsake potential benefits in deference

278 to absolute caution and positions that ignore reasonably foreseeable risks to allow

279 unfettered scientific exploration" [34]. We do not think this is incompatible with the

280 precautionary principle of conservation. The way forward is to acknowledge the

281 potential benefit of new technologies, make measured decisions to integrate new

282 technologies into conservation solutions, and implement ongoing oversight. Further,

283 conservation and synthetic biologists must be open and willing to educate themselves

284 about their respective fields in order to identify ways to bridge the gap and achieve

285 integration. Such an effort would be a powerful, interdisciplinary way to achieve

286 responsible stewardship.

Look to the Past

290 With the advent of classical biological control (CBC) and ecological restoration many

291 of the same concerns about altering natural processes and ecosystems were discussed

292 as are being raised today in the context of synthetic biology applications in the wild.

293 Others have suggested that detailed risk assessments as are regularly used in CBC to

294 evaluate risks and benefits are of use in conservation applications of synthetic biology

$295[28,35]$. We advocate this view and further urge conservation biologists and synthetic

296 biologists to apply the decision frameworks and risk assessments developed for the

297 application of CBC and ecological restoration [36, 37] to intractable conservation

298 issues, to make informed and thoughtful decisions about ecological, political, and 
biological issues surrounding each project before deciding the validity of applying synthetic biology to such issues. Having a framework, including risk assessments and adaptive management [19] for decision-making will serve to highlight conservation issues that are inappropriate candidates for application of synthetic biology and will provide legitimacy for projects that pass the rigors of the framework.

\section{Early and Often}

There has been insufficient engagement between the conservation biology and synthetic biology communities. We are concerned that the accelerated application of synthetic biology to wild systems is outpacing our level of understanding and input. Robust scientific studies need to happen early and often. Further, this research needs to be transparent and to "engage the public early and often"; this message was a common denominator of each of the workshops mentioned earlier. It is likely that the

313 public, including other scientists, are the greatest source of knowledge about potential 314 pitfalls of applying synthetic biology to specific conservation issues and public opinion is likely the biggest hurdle for any project, such as the case studies (Box 1 and Box 2). Without a guiding principle of "early and often" it is likely that synthetic biology will be applied to conservation issues without broad engagement of

318 conservation experts and without the appropriate stakeholder involvement.

\section{Concluding Remarks}

322 Humanity has responsibility to reduce the rate of loss of biodiversity. For this we need 323 to use integrated strategies. It is time for the conservation community to consider the 
324 application of synthetic biology and other new genomic tools. Engagement is urgently 325 needed and it should be based on a series of guiding principles and with a robust

326 decision framework to understand the pros and cons built on existing and new science 327 to maximize biodiversity benefits and minimize biodiversity harm. The conservation 328 community should reach out to the synthetic biology community and with them 329 jointly engage in broad conversations with communities, scientists, and regulators 330 across the globe. The future of nature may depend on our efforts at this critical nexus 331 of biodiversity conservation and technology. 
334 We would like to thank the Rockefeller Foundation for making the workshop at

335 Bellagio Center possible, and all participants for stimulating discussions. Our

336 sincerest thanks to Ben Novak for his tireless help on one of the figures. The

337 conclusions in this article are those of the author(s) and do not necessarily represent

338 the views of the U.S. Department of Agriculture. 


\section{Key References}

341 1. Butchart, S.H.M. et al. (2010) Global biodiversity: indicators of recent declines. Science 328, 1164-1168

2. Rands, M.R.W. et al. (2010) Biodiversity Conservation: Challenges Beyond 2010. Science 329, 1298

3. Tittensor, D.P. et al. (2014) A mid-term analysis of progress toward international biodiversity targets. Science 346, 241-244

4. Butchart, S.H.M. et al. (2015) Shortfalls and solutions for meeting national and global conservation area targets. Cons. Lett. 8, 329-337

5. Sutherland, W.J. et al. (2011) Horizon scan of global conservation issues for 2011. Trends in Ecol. Evol. 26, 10-15

351 6. Noss, R.F. et al. (2012) Bolder thinking for conservation. Cons. Biol. 26, 1-4.

7. Redford, K. et al. (2013) Synthetic biology and conservation of nature: Wicked problems and wicked solutions. PLoS Biology 11: e1001530

8. Johnson, J.A, et al. (2016) Is there a future for genome-editing technologies in conservation? Anim. Cons. 19, 97-101

9. Carlson, R.H. (2010) Biology is technology: The promise, peril, and new business of engineering life. Harvard University Press.

10. Church, G.M. and Regis, E. (2014). Regenesis: how synthetic biology will reinvent nature and ourselves. Basic Books, New York

11. Mali, P. et al. (2013) RNA: guided Human Genome Engineering via Cas9. Science 339, 823-826

12. Esvelt, K.M. et al. (2014) Concerning RNA-Guided Gene Drives for the Alteration of Wild Populations. Ed. Diethard Tautz. eLife 3: e03401 
13. Champer J., A. Buchman, and O.S. Akbari (2016) Cheating evolution: engineering gene drives to manipulate the fate of wild populations. Nature Reviews Genetics. 17, 146-59. 14. Gantz, V.M. et al. (2015) Highly efficient Cas9-mediated gene drive for population modification of the malaria vector mosquito Anopheles stephensi. Proc. Natl. Acad. Sci. U.S.A. 112, 6736-6743

15. Hammond, A. et al. (2016) A CRISPR-Cas9 gene drive system targeting female reproduction in the malaria mosquito vector Anopheles gambiae. Nat. Biotechnol. 34, 78-83

16. A call for conservation with a conscience: no place for gene drives in science (2016); http://www.synbiowatch.org/wpcontent/uploads/2016/08/ETC_letter_vs_genedrives_v5.pdf

17. Redford, K.H. et al. (2014) Synthetic biology and the conservation of biodiversity. Oryx 48, 330-336

18. Taylor, H.R. and N.J. Gemmell (2016) Emerging technologies to conserve biodiversity: further opportunities via genomics. Response to Pimm et al. Trends in Ecol. Evol. 31, 171-172

19. Salafskay, N.et al. (2002) Improving the practice of conservation: a conceptual framework and research agenda for conservation science. Cons. Biol. 16, $1469-1479$

20. McCarthy, D.P. et al. (2012) Financial costs of meeting global biodiversity conservation targets: Current spending and unmet needs. Science 338, 946-949

21. Hoffman M. et al. (2015) The difference conservation makes to extinction risk of the worlds ungulates. Cons. Biol. 29, 1301-1313

22. Hoegh-Guldberg, O. et al. (2008) Assisted colonization and rapid climate change. Science 321, 345-346 
23. Seddon, P.J. et al. (2014) Reversing defaunation: Restoring species in a changing world. Science 345, 406-412

24. Ricciardi, A. and Simberloff, D. (2009). Assisted colonization is not a viable conservation strategy. Trends in Ecol. Evol. 24, 248-253

25. Ricciardi, A. and Simberloff, D. (2014) Fauna in decline: first do no harm. Science 345,884

26. Soulé, M.E., Wilcox, B.A., eds. (1980) Conservation biology: An evolutionaryecological perspective. Sunderland, Mass., Sinauer.

27. SynBioWatch, Civil Society Perspectives on Synthetic Biology (2016). Reckless driving: Gene drives and the end of nature. http://www.synbiowatch.org/2016/08/reckless-driving/

28. National Academies of Sciences, Engineering, and Medicine (2016) Gene Drives on the Horizon; Advancing Science, Navigating Uncertainty, and Aligning Research with Public Values. The National Academies Press

29. World Health Organization (2014) The guidance framework for testing genetically modified mosquitoes. World health organization, programme for research and training in tropical diseases

30. U.S. Government (2016) Modernizing the Regulatory System for Biotechnology Products: An Update to the Coordinated Framework for the Regulation of Biotechnology.https://www.whitehouse.gov/sites/default/files/microsites/ostp/ biotech_coordinated_framework.pdf

31. IUCN (2016) Motion 095 - Development of IUCN policy on biodiversity conservation and synthetic biology. Adopted at WCC 2016 in Hawai'i, United States, 1-10 September 2016. https://portals.iucn.org/congress/motion/ 
32. Carlson, R.H. (2016) Estimating the biotech sector's contribution to the US economy. Nat. Biotechnol. 34, 247-255

33. Presidential Commission for the Study of Bioethical Issues (2010) New Directions: the Ethics of Synthetic biology and Emerging Technologies. (http://bioethics.gov/cms/synthetic-biology-report)

34. Gutmann, A. (2011) The ethics of synthetic biology: Guiding principles for emerging technologies. Hastings Cent. Rep. 41, 17-22

35. Webber, B.L. et al. (2015) Is CRISPR-based gene drive a biocontrol silver bullet or global conservation threat? Proc. Natl. Acad. Sci. U.S.A. 112, 10565-10567

36. Charudattan, R. (2005) Ecological, practical, and political inputs into selection of weed targets: What makes a good biological control target? Biol. Control 35, 183-196

37. Pastorok, R.A. et al. (1997) An ecological decision framework for environmental restoration projects. Ecol. Eng. 9, 89-107

38. Capizzi, D. (2014) Rating the rat: global patterns and research priorities in impacts and management of rodent pests. Mamm. Rev. 44, 148-162

39. Blackburn, T.M. (2004) Avian Extinction and Mammalian Introductions on Oceanic Islands. Science 305, 1955-1958

40. Simberloff D et al. (2013) Impacts of biological invasions: what's what and the way forward. Trends in Ecol. Evol. 28, 58-66

41. Jones H.P. et al. (2016) Invasive mammal eradication on islands results in substantial conservation gains. Proc. Natl. Acad. Sci. U.S.A. 112, 4033-4038

42. Towns D.R. and \& K. G. Broome (2003) From small Maria to massive Campbell: Forty years of rat eradications from New Zealand islands, New Zealand $J$. Zool. 30, 377-398 
43. Dowling DK, Tompkins DM, Gemmell NJ (2015) The Trojan Female Technique for pest control: a candidate mitochondrial mutation confers low male fertility across diverse nuclear backgrounds in Drosophila melanogaster. Evol. Appl. 8, 871-880.

44. Johnson, T.H. and Stattersfield A.J. (1990) A global review of island endemic birds. Ibis 132, 167-180.

45. Paxton, E.H. et al. (2016) Collapsing avian community on a Hawaiian Island. Sci. $A d v .2: \mathrm{e} 1600029$

46. van Riper III C. et al. (1986) The Epizootiology and Ecological Significance of Malaria in Hawaiian Land Birds. Ecol. Monogr. 56, 327-344

47. LaPointe, D.A. et al. (2012) Ecology and conservation biology of avian malaria. Ann. N. Y. Acad. Sci. 1249, 211-226

48. LaPointe, D.A. et al. (2009) Managing disease. In Conservation Biology of Hawaiian Forest Birds. T.K.Pratt, C.T.Atkinson,P.C. Banko, J. Jacobi, \& B.L.Woodworth, Eds.: 405-424. Yale University Press. New Haven.

49. Alphey, L. (2014) Genetic control of mosquitoes. Ann. Rev. Ent. 59, 205-224

50. Champer, J. et al. (2016) Cheating evolution: engineering gene drives to manipulate the fate of wild populations. Nat. Rev. Gen. 17,146-159

51. Sutherland, W.J. et al. (2014). A horizon scan of global conservation issues for 2014. Trends in Ecol. Evol. 29, 15-22

52. Campbell, K.J. et al. (2015) The next generation off rodent eradications: innovative technologies and tools to improve species specificity and increase their feasibility on islands. Biol. Cons. 185, 47-58

53. Sutherland, W.J. et al. (2016) A horizon scan of global conservation issues for 2016. Trends in Ecol. Evol. 31, 44-53 
463 54. Sutherland, W.J, et al. (2010) A horizon of global conservation issues for 2010. Trends in Ecol. Evol. 25, 1-6

465 55. Ainsworth, T.D. et al. (2016). Climate change disables coral bleaching protection on the Great Barrier Reef. Science 352, 338-342

467 56. Jin, Y.K. et al. (2016) Genetic markers for antioxidant capacity in reef-building 468 corals. Sci. Adv. 2, e1500842 
Table 1:

470

471

472

Major conservation problems with possible solutions applying synthetic biology approaches. 


\section{Box 1 Eradication of invasive rodents}

In total only 147 of the more than 2,000 species of rodents worldwide are considered norvegicus, and house mouse Mus musculus) have by far the greatest negative impacts on the system in which they invade, particularly on endemic fauna on island systems [38]. Rodent invasions of islands have resulted in the extinction of hundreds of species of native birds [39], particularly seabirds, and thereby disrupting the flow of nutrients from the ocean to the land [40].

Invasive mammal eradication on islands is a major conservation tool, and rodents are the most common targets for eradication [41]. The principal approach to rodent eradication on islands involves the use of poisons, particularly the aerial broadcast of non-selective anticoagulants [42]. Although there are alternative techniques that do not require toxins [(e.g., 43], toxicants are still considered the most effective. There are concerns about development of anticoagulant resistance in target species, and about the effects of poisons on non-target species, but it has been suggested that the search for alternative techniques has not yet been fruitful [38].

Experimental work currently underway is exploring the feasibility of a synthetic

493 biology solution to the problem of invasive rodents through the creation of mice with 494 a gene from the Y chromosome inserted onto chromosome 17 (autosome) that results 495 in the production of only male offspring (Figure 1). The release of these modified 496 mice (SRY mice) into a natural population therefore has the potential to eventually 497 breed that population out of existence as males predominate, reproduction ceases, and 
498 the remaining animals die of old age. The numbers of modified inoculants that would 499 need to be released, and the time frames to extinction, remain uncertain. The risks of 500 such an approach include the accidental translocation or natural dispersal of $\mathbf{G M}$ 501 rodents to other, non-target rodent populations; possible hybridization between GM

502 individuals and endemic rodent species; public opposition to the environmental

503 release of a GM animal, and unanticipated ecosystem effects following successful 504 rodent eradication. Mitigation of risks could entail a focus on isolated oceanic islands 505 that have no human inhabitants nor endemic rodents, but to which access can be 506 strictly regulated. Many such islands exist in the Oceania region, on which invasive 507 rodents have heavily impacted the endemic fauna. Early field trial success on oceanic 508 islands might facilitate public acceptance of synthetic biology solutions to 509 conservation challenges, and would additionally enable the refinement of lab and field 510 protocols, and the specificity of risk-cost assessments. Strategies for mitigation might 511 include the use of reversible gene drives, or traditional application of rodenticides. 
514 More than $90 \%$ of bird extinctions during historic times have occurred on islands, and

515 the Hawaiian Islands have lost a greater proportion (34\%) of their endemic bird

516 species than any other system [44]. It is estimated that 71 of the 113 endemics became

517 extinct, and over three quarters of those left are endangered. Further, range

518 contraction of endemic birds of Kaua $i$ has appeared to accelerate since 2000, and

519 multiple extinctions are predicted in the next decade [45] While significant losses

520 occurred as a result of the impacts of invasive species, and due to exploitation and

521 habitat destruction following the arrival of humans, it is believed that after the 1920s

522 the principal cause of extinction and decline has been avian malaria, caused by

523 protozoan parasites in the genus Plasmodium, and transmitted by the mosquito vector

524 Culex quinquefasciatus that was introduced to the islands in 1826 [46]. Global

525 warming is predicted to increase the impact of avian malaria in Hawai'i as mosquitoes

526 expand their range into high-altitude refugia [47]. Traditional approaches to the

527 control of mosquito-borne disease have focussed on reducing the abundance of

528 vectors through removal of larval habitat, chemical control of adults and larvae, or

529 biological control using predators or microbial pathogens [48]. Such approaches are

530 difficult to apply over large areas of rugged terrain, and/or would have unacceptable

531 impacts on native invertebrates, therefore there have been calls for innovative

532 techniques to control avian malaria transmission [47].

533

534 A synthetic biology solution to avian malaria vector control takes the form of a

535 variation on the traditional Sterile Insect Technique (SIT), whereby the DNA of

536 invasive male mosquitoes is damaged, e.g. through irradiation, and the mass release 
of sterile males overwhelms the invasive wild population. A more precise synthetic biology solution uses genetic modification to disrupt normal cell function. The RIDL

539 technique, the release of insects carrying a dominant lethal genetic system, entails the

540 release of genetically modified male mosquitoes whose offspring would inherit a self-

541 limiting gene and die before becoming functional adults (Figure 2). Field trials of

542 mosquito vector control using the RIDL technique have been conducted since 2009,

543 and have successfully suppressed target populations of Aedes aegypti in the Cayman

544 Islands, Brazil, and Panama [49]. To date, trials have used a self-limiting approach,

545 requiring repeated mass release of genetically modified males. But a self-sustaining

546 control would be possible using a gene-drive system, eliminating the need for ongoing

547 releases, but potentially being harder to monitor and adjust in a natural population

$548[49,50]$. Some conservation biologists believe this might be an effective management

549 tool for the endemic birds of Kaua i [45]

551 Risks from using a gene drive approach to the control of avian malaria in the

552 Hawaiian Islands include the loss of efficacy due to evolved resistance to the lethal

553 gene [49]; the escape of transgenic mosquitoes to other natural systems; disruption of

554 any process whereby endemic species acquire natural immunity to Plasmodium

555 infection; and societal resistance to the environmental release of a GMO. The

556 challenge, and opportunity, is for the conservation community to work with synthetic

557 biologists to design the appropriate approach: disrupt the vector's ability to transmit

558 the parasite or drive the vector to local extinction? 
Figure legends:

Figure 1: SRY Gene Drive in mice

562 To skew sex ratios in naturally breeding populations, the male determining gene (Sry), normally found on Chromosome (Chr) Y, can be inserted into a naturally occurring gene drive element on Chr 17 called the t-complex. The t-complex is passed down to greater than $90 \%$ of the offspring through the paternal side. A) The X and $\mathrm{Y}$ chromosomes are shown, with the Sry gene on Chr Y, as well as on any autosome (autosome 1 is shown as an example) and in the t-complex. B) In normal breeding scenarios, the Sry gene is located only on Chr Y and therefore only mice inheriting Chr Y are male, therefore approximately $50 \%$ of the offspring are XY (male) and $50 \%$ are XX (female). C) In a breeding scenario where the Sry gene has been added to an autosome, approximately $75 \%$ of the offspring will be male and $25 \%$ will be female. The $*$ denotes the scenario where the mouse is chromosomally female but phenotypically male. D) In breeding scenarios where the male carries the Sry gene within the Chr $17 \mathrm{t}$-complex, over $90 \%$ of offspring will inherit the t-complex containing autosome. It is predicted that fewer than $10 \%$ of the offspring will be XX (female), with the remaining being phenotypically male, including either XY (male) or XX (sterile male).

Figure 2: Engineering sterile mosquitos

(a) A population homozygous for a repressible female-specific lethal can be massreared by providing the repressor (chemical "antidote") during rearing. (b) Cohorts intended for field release are reared in the absence of the repressor, so females die. This rearing could be in the factory, as shown, or in the field if eggs were released, perhaps into artificial larval habitats. (c) The males are released to court and mate wild vector females. (d) Offspring of such mating are heterozygous for the dominant female-lethal gene so females die. (e) Heterozygous males can mate additional wild females, inducing some further female mortality. The female-lethal effect means that the construct has a high fitness cost and will disappear rapidly from the population unless replaced by periodic release of additional homozygous males (a-c). 


\section{Glossary:}

Biodiversity - biological diversity, sum of variation in ecosystems, species and genes

CRISPR/Cas9 - (clustered regularly interspaced short palindromic repeats) biochemical method to efficiently cut and edit DNA - using a specific Protein (Cas9)

De-extinction - the development of functional proxies of species which have previously gone extinct

Gene drive - technique for spreading selected, usually recombinant, DNA sequences (genes) through wild populations with the aim of getting rid of unwanted characteristics of an organism or adding desired characteristics. This is a naturally occurring process of "selfish-genes" that is now being harnessed to spread genome edits through a population rapidly

Genome editing - making targeted changes to an organism's genome - mostly by using specific endonucleases such as CRISPR/Cas9

\section{GM - genetically modified (see also GMO), aka genetically engineered (GE)}

GMO - genetic modified organism, also living modified organism (LMO), is an organism whose characteristics have been changed by genetically engineering (contrasting classical selection experiments or naturally by mating and/or recombination)

iGEM - international genetically engineered machine - organization dedicated to education and the advancement of synthetic biology and the development of an open community and collaboration (igem.org)

RIDL - Release of insects carrying a dominant lethal gene or genetic system

SIT - sterile insect technique, where sterile individuals of a species generated in the lab (e.g. through radiation) are generated

Synthetic biology - Application of science, technology and engineering to facilitate and accelerate the design, manufacture and/or modification of genetic materials in living organisms (from http://ec.europa.eu/health/scientific_committees/consultations/public_consultations/sc enihr_consultation_21_en.htm)

SRY mice - SRY is a gene determining sex that regulating testis differentiation, in these mice this gene is placed on the autosome and offspring are only male.

Sterile male - sterile males are released to nature so when mating with wild females there is no offspring. Males are sterilized either through radiation (previously) or by genetic manipulation 
A. Examples of SRY gene knock-ins

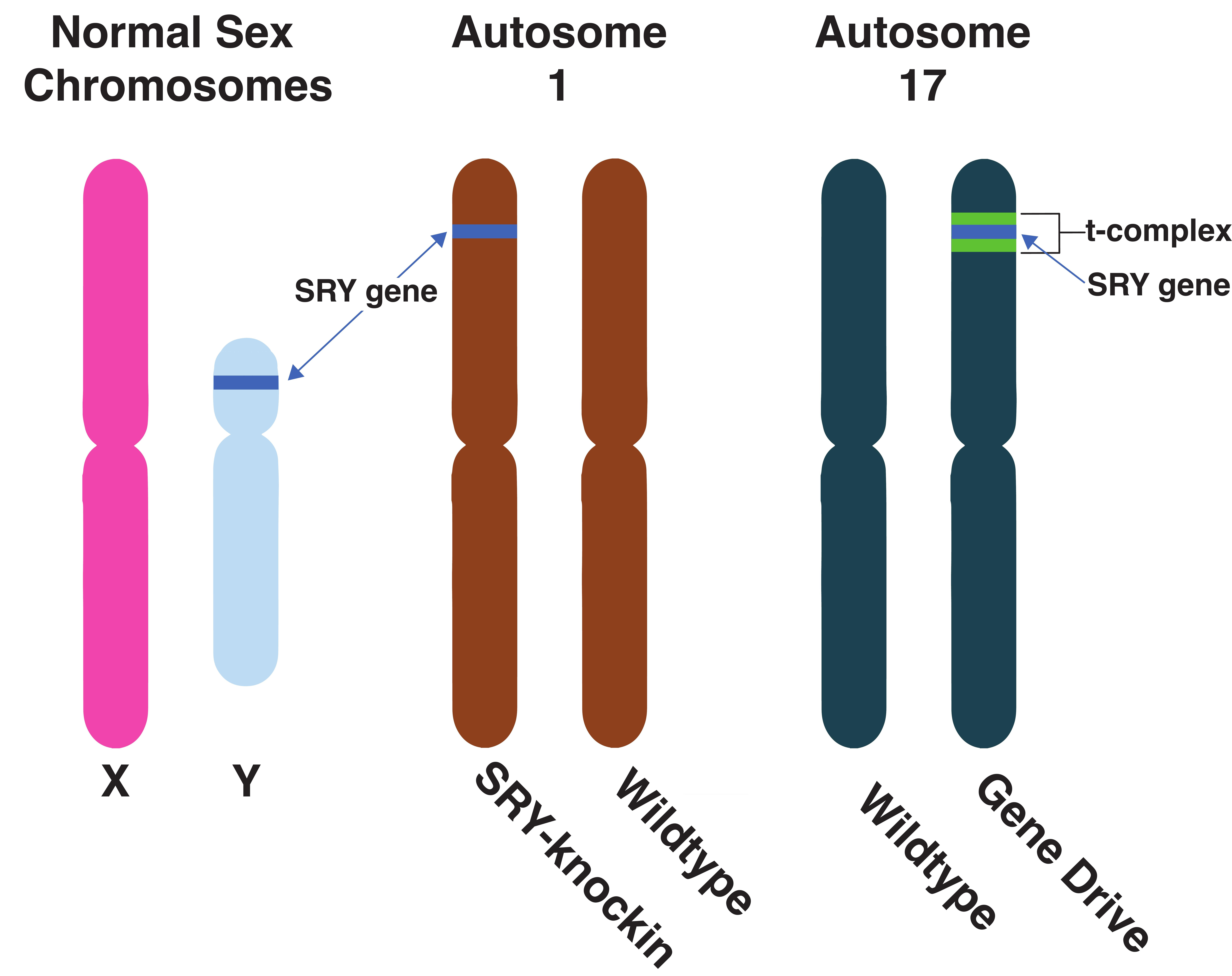

B. Normal Sex Ratio ( $50 \%$ SRY inheritance)
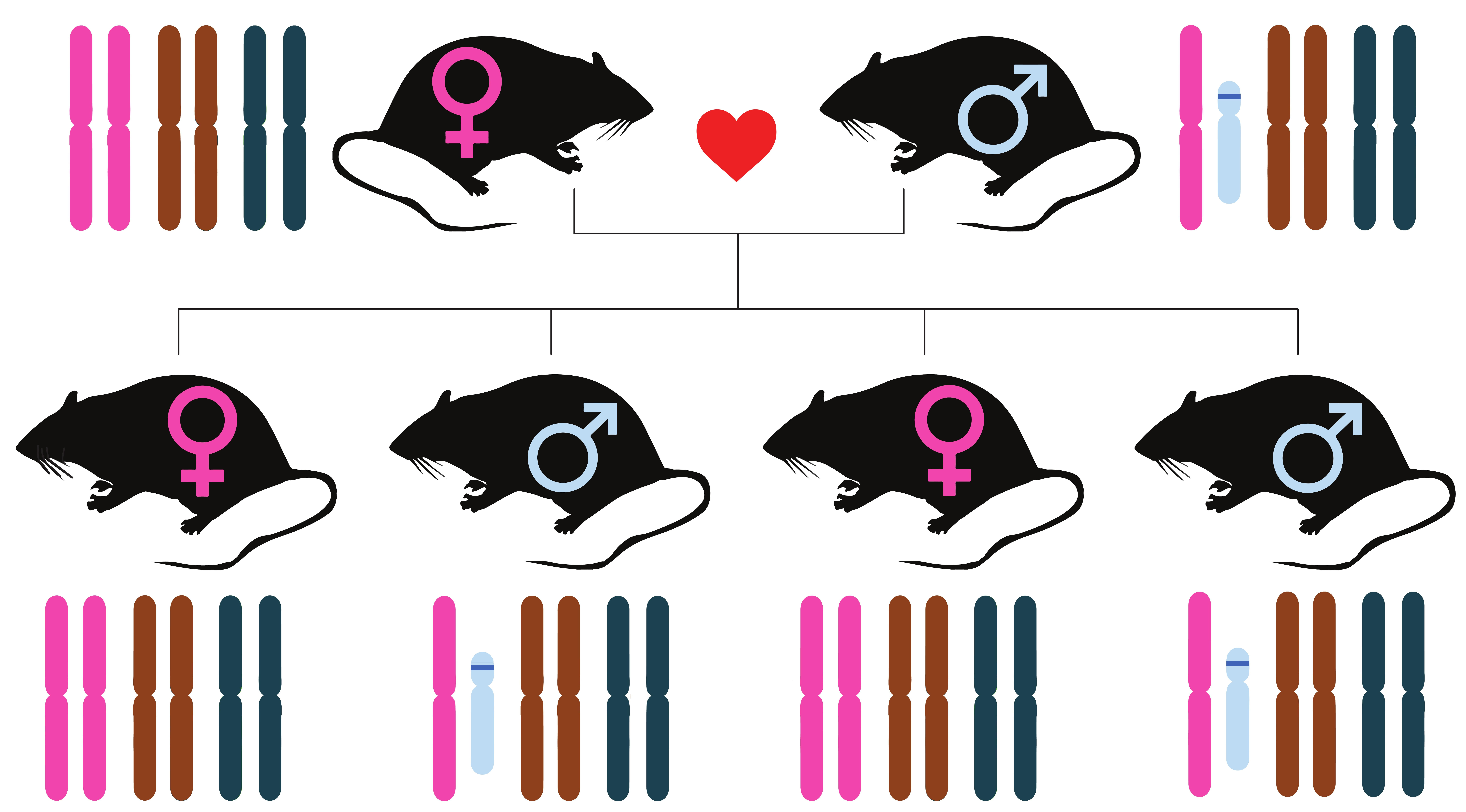

C. Autosomal SRY-knockin ( $75 \%$ SRY inheritance)
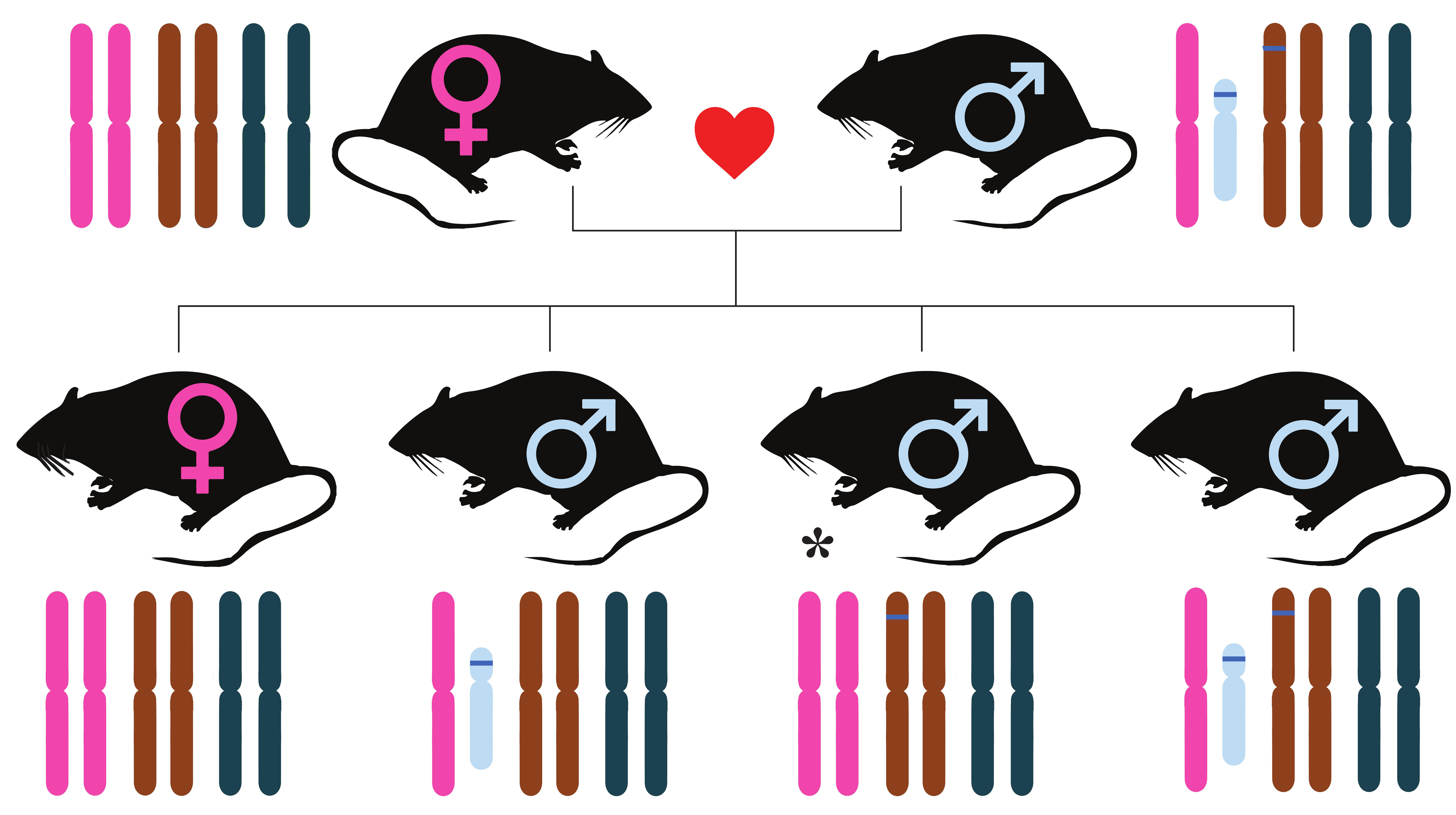

D. T-complex SRY-Gene Drive ( $\geq 90 \%$ SRY inheritance)
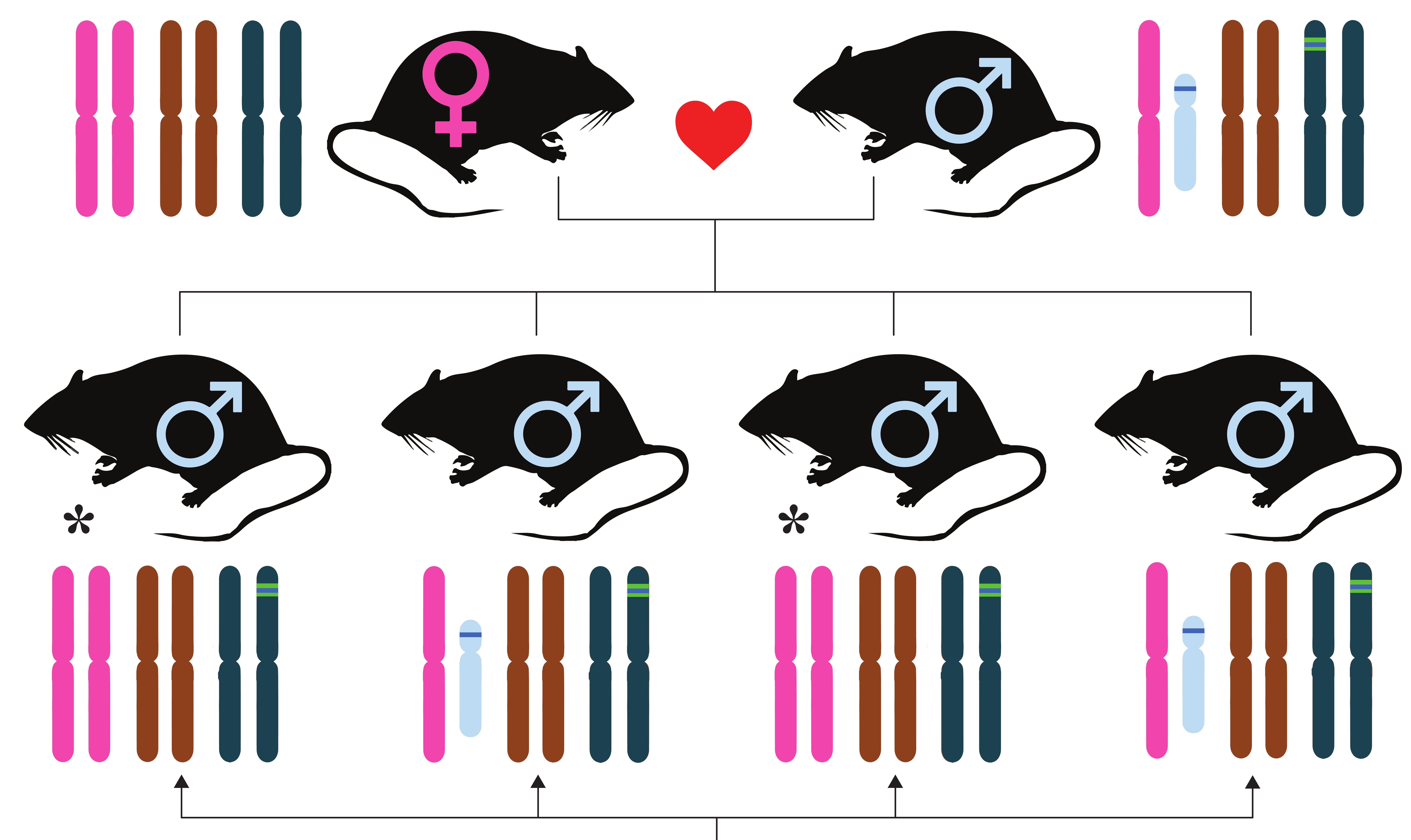

Wildtype autosome 17 only inherited maternally.

Paternal wildtype autosome 17 inheritance prevented by SRY+ t-complex. 


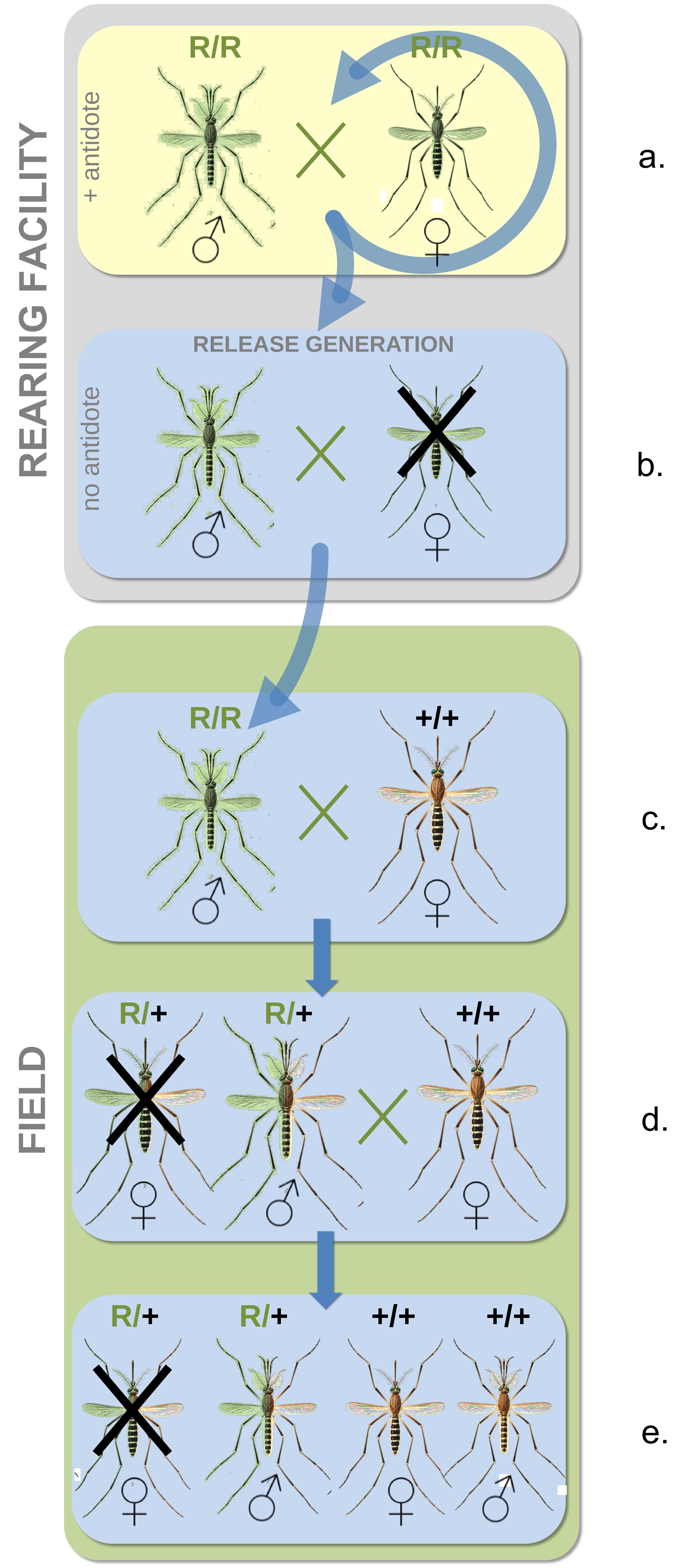




\begin{tabular}{|c|c|c|c|}
\hline Conservation Issues & Biodiversity Issues & Synthetic Biology Solutions & References \\
\hline \multirow[t]{2}{*}{ Invasive Species } & Mice and rats on islands & See Box 2 & [8] [17] [51] [52] \\
\hline & Brown tree snake (Boiga irregularis) in Guam & $\begin{array}{l}\text { Use Y chromosome alterations and gene drives to stop reproduction in this } \\
\text { species }\end{array}$ & [17] \\
\hline \multirow[t]{3}{*}{ Pathogens } & Avian blood parasites in Hawaiian birds & See Box 3 & [5] [49] [51] \\
\hline & $\begin{array}{l}\text { Fungal pathogens: White-nose Syndrome in North } \\
\text { American bats and Chytrid fungus in amphibians, and } \\
\text { snakes }\end{array}$ & Engineer genetic resistance to fungal diseases & {$[17][18][51]$} \\
\hline & Plague in black-footed ferrets & $\begin{array}{l}\text { Use CRISPR/CAS } 9 \text { to cut out part of genome that is susceptible to disease and } \\
\text { replace with genetic code for disease resistance }\end{array}$ & [18] \\
\hline \multirow[t]{3}{*}{ Habitat Conversion } & Palm Oil & $\begin{array}{l}\text { Use other plants or systems to produce manmade palm oil and take pressure off } \\
\text { current production methods and thus reduce tropical forest conversion }\end{array}$ & [2] \\
\hline & $\begin{array}{l}\text { Productivity of soils reduced from pesticides and } \\
\text { herbicides or mining practices such as gold or strip }\end{array}$ & $\begin{array}{l}\text { Synthetically restore microbiome of soils for habitat restoration, engineer plants } \\
\text { that require less pesticides/herbicides for production }\end{array}$ & [5] \\
\hline & Extraction of and use of fossil fuels & $\begin{array}{l}\text { Provide alternative solutions and thus alleviate pressures on such resources and } \\
\text { the damage they cause such as habitat loss and pollution. Create and modify a } \\
\text { micro-organisms to consume hydrocarbons to clean up oil spills }\end{array}$ & {$[17][51]$} \\
\hline \multirow[t]{3}{*}{ Loss of Biodiversity } & $\begin{array}{l}\text { Agriculture and its limitations to feed and house (forests) } \\
\text { a growing human population }\end{array}$ & $\begin{array}{l}\text { New food sources or ways to produce food without pesticides and large tracts of } \\
\text { arable land }\end{array}$ & {$[2][8]$} \\
\hline & Loss of faunal and floral biodiversity & Create ecological proxies, restore ecological functions & [2] \\
\hline & Revive and restore extinct species & $\begin{array}{l}\text { "De-extinction" (e.g. woolly mammoth) use an existing species (elephant) and } \\
\text { alter its genome to incorporate genetic code from the extinct species and create a } \\
\text { proxy species that hopefully fills the same ecological role as the extinct species }\end{array}$ & [17] [51] \\
\hline \multirow[t]{3}{*}{ Overexploitation } & Rhino horn, ivory and deep sea sharks for squalene & Produce molecule that is a substitute and can be manmade & [51] [53] \\
\hline & Pet trade and feral domestic animals & Produce sterile pets & [51] \\
\hline & Fish species & Improve aquaculture for higher protein production & (A) \\
\hline \multirow[t]{4}{*}{ Pollution } & $\begin{array}{l}\text { Replacing things made from petroleum and synthetic } \\
\text { rubber }\end{array}$ & Engineered plants to make the same products & [51] \\
\hline & Pesticide use & Increase resistance to pests & (B) \\
\hline & $\mathrm{CO} 2$ emissions or other greenhouse gases & Biofuels from synthetic Algae & [5] [17] \\
\hline & Pharmaceuticals in the environment & Create or modify a micro-organisms to consume or degrade pharmaceuticals & [17] \\
\hline
\end{tabular}




\begin{tabular}{|l|l|l|l|}
\hline & Micro-plastics in ocean and soils & Create or modify a micro-organisms to consume or degrade micro-plastic \\
\hline & Water pollution & Create and modify algal or bacterial species that consume or degrade pollutants & [2] \\
\hline & Coral Reef Bleaching & $\begin{array}{l}\text { Alter coral reef genome for resistance borrowing pathways from coral species } \\
\text { that seem to withstand increased temperature and/or acidity }\end{array}$ & \begin{tabular}{l} 
[2] [17] [55] [56] \\
\hline
\end{tabular}
\end{tabular}

(A) http://www.fda.gov/downloads/AnimalVeterinary/DevelopmentApprovalProcess/GeneticEngineering/GeneticallyEngineeredAnimals/UC M466218.pdf (B) http://www.nap.edu/catalog/23395/genetically-engineered-crops-experiences-and-prospects 